if mere examination of blood films is sufficient, it is important that we know the fact as soon as possible. I am, Sir, yours faithfully,

Colwall, April 12th, 1915. MaRy H. Williams.

To the Editor of THE LANCET.

SrR,-The very interesting report of a case of the above disease sent by Dr. Alfred C. Coles to THE LANCE' of April 10th will, I hope, be followed by other reports where early blood examinations have been made. If the meningococci are to be generally found in the blood it will be useful for early diagnosis, especially for practitioners in the country who may not have, or be able to procure, the necessary instrument for lumbar puncture. In the case of the blood being found infected it will give us an opportunity to try the soamin treatment described by Dr. George Low in the British Medical Journal of Feb. 27th last, and also used by Mr. E. Norman Butler in British East Africa and Aescribed in THE LANCET of April 3rd.

In a case I had recently the symptoms tallied with those of Dr. A. D. Edwards's case as quoted by Dr. Coles-viz., intense pain in the lumbar region and vomiting and no head retraction-I notice the early symptoms of the African native cases were intense headache and head retraction. In my case meningo. cocci were found after lumbar puncture, but blood was not examined. After consultation with Dr. Hyla Greves, of Bournemouth, soamin was tried and :seemed to benefit the patient for a fortnight, but the case then got rapidly worse and Flexner's serum was used, though too late, as the patient died on the twentieth day after onset. I hope statistics will soon be published showing the mortality rate of the disease, where serum has been used and where not. I am, Sir, yours faithfully,

Christehurch, Hants, April 11th, 1915. W. Moss BRIsTow.

\section{ANGINA PECTORIS.}

To the Editor of THE LANCET.

SIR,-I am much interested in the letter of Dr. Edgar Lea on a case of angina pectoris, in your issue of April 10th. The case was one of syphilitic aortitis with angina, and needs no particular "segmental" or other "neurosis" to explain it. Dr. Lea's able letter gives precisely the data wanted in such cases. But I wish to thank him especially for his careful observations concerning tender points. Their physiological interest is great, but, like Dr. Lea, I have found them too fugitive and inconstant for clinical use; and this opinion I have diffidently ventured to state already in my book on arterial disease, which now-after long delays due to the war-will, I trust, soon be published.

I am, Sir, yours faithfully,

Cambridge, April 10th, $1915 . \quad$ CLIFFORD ALLBUTT.

\section{HEALTH RESORTS FOR CONVALESCENCE AND SICK LEAVE IN THE ARMY.}

$$
\text { To the Editor of THE LANCET. }
$$

SIR,-You have described in a leading article in the last issue of THE LANCET with unanswerable force the hiatus that begins after hospital treatment, and ends either in restoration to health or in chronic disability. It is to be feared that this period of convalescence is often unnecessarily painful and prolonged, and that, indeed, it frequently fails of its effects for want of continued medical care and supervision. Many of the excellent convalescent homes abundantly provide for an uncomplicated recovery, but, as you suggest, there are a very large number of cases in which a continuance of special care and treatment is needful.

Experience has shown that spas and other health resorts are the proper places for these cases. The treatment at health resorts of military cases has been amply justified already in this country, although, happily, on a comparatively small scale. We need only refer to such common conditions as painful wounds, post-operative cases, nervous disorders from shock and injury, rheumatism, tachycardia, \&c. For the very large numbers now in contemplation special arrangements are of course requisite, but there is no lack of willing service at the health resorts, and all their resources are freely offered for wounded and invalid soldiers.

A committee of the Council of the Section of Balneology and Climatology of the Royal Society of Medicine has been engaged in collating the necessary information and supplying it to the military authorities. They have prepared a short pamphlet which includes: (1) a summary of the medical and surgical maladies most commonly met with in the military hospitals, for which spa treatment at a health resort is indicated; and (2) a list of the British spas, as well as other bathing establishments, with the factors influencing the preference for one or another in the treatment of such maladies.

It is the aim of the committee in association with local committees and representatives throughout the country to fill the hiatus to which you have referred by organising a scientific after-treatment at our many valuable health stations. They also have in hand a proposal for furnishing to the War Office returns of the accommodation available, both for men and officers.

The practical carrying out of such a work on a large scale naturally presents some difficulties. To one of these you refer. Medical men, without, at all events, temporary military rank, are often at a loss when in charge of military cases. There is also the larger difficulty how to provide an efficient and scientific distribution of the large numbers of cases leaving the great hospitals, so that each man may be sent to the locality where he will receive the greatest benefit. These and other problems present, however, no insuperable diff. culties. They are mainly questions of machinery. The great and encouraging fact is the willingness of all concerned to do their part.

We are, Sir, yours faithfully, R. Fortescue Fox,

April 11th, 1915 J. CAMPBeli McCluRe.

\section{"THE MINOR HORRORS OF WAR." To the Editor of THE LANCET.}

SIR,-Although the first edition of my little book on the above subject was a large one, a second edition is already being called for.

As I am anxious to make the book as useful as possible, I should be grateful if any medical man who has had actual experience in dealing with Pediculus vestimenti and Pediculus capitis, and who knows of remedies other than those mentioned in the first edition, would communicate with me at the address given below.

I am, Sir, yours faithfully,

A. E. SHIPLEY.

Christ's College Lodge, Cambridge, April 12th, 1915. 